\title{
OBSERVATIONAL PROPERTIES OF THE SHAKHBAZIAN GROUPS SHKH 30 AND SHKH 360
}

\author{
H. TIERSCH ${ }^{1}$, H. OLEAK ${ }^{1}$, D. STOLL ${ }^{1}$ and H. BÖHRINGER ${ }^{2}$ \\ ${ }^{1}$ WIP-Gruppe "Astronomie" bei der Universität Potsdam, An der Sternwarte 16, \\ D-14482 Potsdam, Germany \\ ${ }^{2}$ MPI Extraterrestrische Physik, D-85740 Garching, Germany
}

X-ray emission has been detected from 12 compact groups of galaxies of the Shakhbazian catalogue (out of 27 investigated groups) with the ROSAT PSPC all-sky survey. The groups Shkh 30 (Shakhbazian 1973) and Shkh 360 (Petrosian 1978) are presented here (Figs. 1 and 2).

Considering the detection of X-ray emission of the NGC 2300 group of galaxies (Mulchaey et al. 1992) as well as of Shakhbazian galaxy groups (Tiersch et al. 1993a, b), hot diffuse X-ray emitting intergalactic gas in groups of galaxies is not the exception but rather a common phenomenon.

There exist measured redshifts for five galaxies of the group Shkh 30 (Amirkhanian 1989). The derived parameters are seen in Table 1. The Shakhbazian group 360 is not investigated optically. The measured ROSAT PSPC X-ray data for Shkh 30 and Shkh 360 are presented in Table 2.

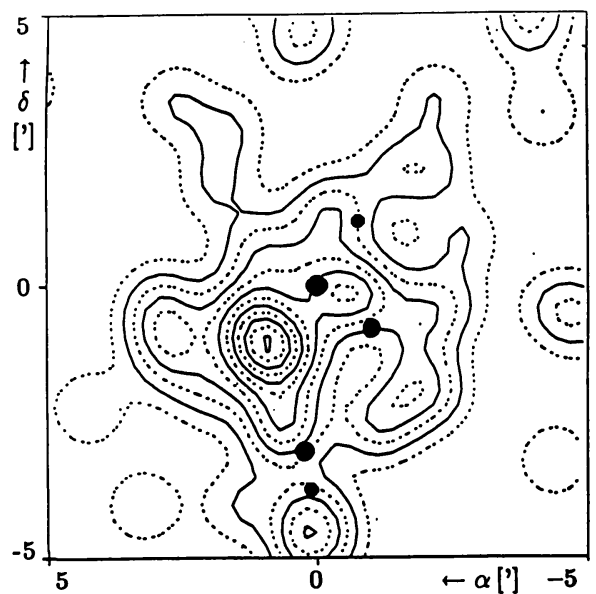

Figure 1. Shakhbazian 30.

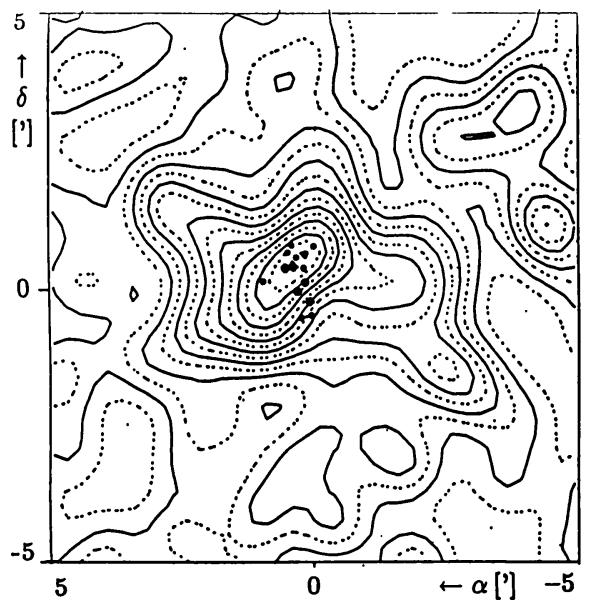

Figure 2. Shakhbazian 360.

H. T. MacGillivray et al. (eds.), Astronomy from Wide-Field Imaging, 623-625.

(C) 1994 IAU. Printed in the Netherlands. 
Table 1. The parameters of Shkh 30 and Shkh 360

\begin{tabular}{|c|c|c|c|c|c|c|c|c|}
\hline $\begin{array}{c}\text { Group } \\
\text { No. }\end{array}$ & $\begin{array}{c}\alpha \\
(2000)\end{array}$ & $\begin{array}{c}\delta \\
(2000)\end{array}$ & $z$ & $\begin{array}{c}d \\
{[\mathrm{Mpc}]}\end{array}$ & $\begin{array}{c}\sigma \\
{[\mathbf{k m} / \mathbf{s}]}\end{array}$ & $\begin{array}{c}D \\
\text { [kpc] }\end{array}$ & $\begin{array}{c}M_{\text {rit }} \\
{\left[10^{13} M_{d}\right]}\end{array}$ & $\begin{array}{r}M / L \\
{\left[M d L_{d}\right]}\end{array}$ \\
\hline 30 & $23^{\mathrm{b}} 47^{\mathrm{m}} 23^{\circ}$ & $-02^{\circ} 18^{\prime} 02^{\prime \prime}$ & 0.0202 & 110 & 300 & 131 & 1.3 & 110 \\
\hline 360 & $15^{\mathrm{h}} 41^{\mathrm{m}} 26^{\mathrm{c}}$ & $+04^{\circ} 43^{\prime} 52^{\prime \prime}$ & & & & & & \\
\hline
\end{tabular}

Table 2. ROSAT PSPC data for Shakhbazian groups

\begin{tabular}{ccccc}
\hline $\begin{array}{c}\text { Group } \\
\text { No. }\end{array}$ & $\begin{array}{c}\text { counts PSPC } \\
(0.4-2.4 \mathrm{keV})\end{array}$ & $\begin{array}{c}\text { exposure } \\
{[\mathrm{s}]}\end{array}$ & $\begin{array}{c}\text { countrate } \\
{\left[\mathrm{s}^{-1}\right]}\end{array}$ & $\begin{array}{c}\text { Luminosity[1012 erg/s] } \\
(0.1-2.4 \mathrm{keV})\end{array}$ \\
\hline 30 & $47( \pm 8)$ & 428 & 0.11 & 86 \\
360 & $57( \pm 9)$ & 500 & 0.11 & \\
\hline
\end{tabular}

For a large data sample of clusters of galaxies, a correlation between X-ray luminosity and velocity dispersion was found by Quintana \& Melnick (1982) $L_{x}=4.2 \cdot 10^{44} \mathrm{erg} / \mathrm{s}\left(\sigma_{/} / 10^{3} \mathrm{~km} / \mathrm{s}\right)^{n}$ (see Sarazin 1988). The crucial point is the exponent $n$ in the $L_{x} \sim \sigma$-correlation. Quintana \& Melnick (1982) found that member-rich clusters tend to be stronger X-ray sources than the member-poor clusters and, therefore, a value of $n \approx 3$ for poor clusters of galaxies was derived contrary to $n \approx 4$ for rich clusters. If galaxy groups represent the extreme end of poor clusters, our data (further groups have been presented by Tiersch et al. 1993a, b) do not support the distinction between poor and rich galaxy clusters (see Fig. 3). This means that the $L_{x} \sim \sigma^{4}$ relationship in compact galaxy groups seems to be a simple extension of the properties of galaxy clusters.

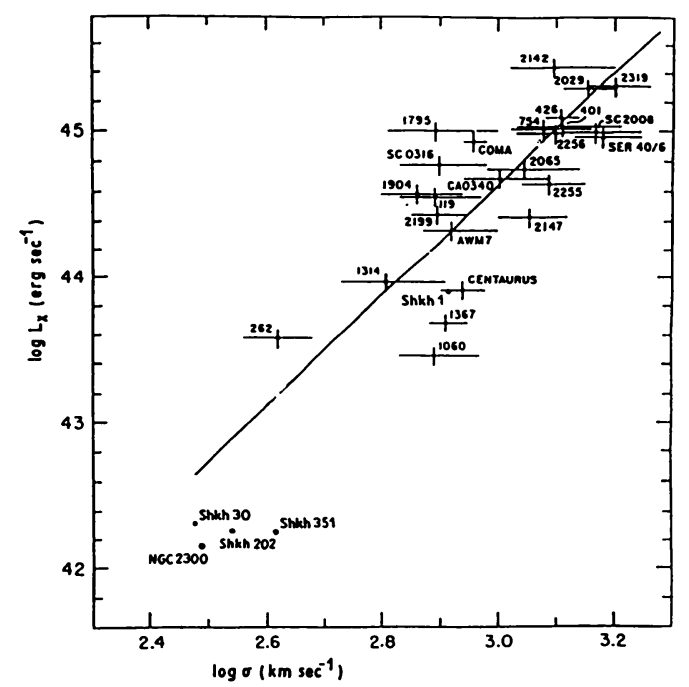

Figure 3. Correlation between luminosity and the velocity dispersion. 


\section{References}

Amirkhanian, A.S., 1989. Soobshch. Byurak. Obs., 61, 27.

Mulchaey, J.S. Davis, D.S., Mushotzky, R.F. and Burstein, D., 1993. Astrophys. J. Lett., 404, L9.

Quintana, H. and Melnick, J., 1982. Astron. J., 87, 972.

Petrosian, M.B., 1978. Astrofizika, 14, 631.

Sarazin, C.L., 1988. 'X-Ray Emission from Cluster of Galaxies', Cambridge University Press.

Shakhbazian, R., 1973. Astrofizika, 9, 496.

Tiersch, H., Stoll, D., Oleak, H. and Bohringer, H., 1993a. 'Observational properties of Shakhbazian groups'. Poster presented at the Spring Meeting of the Astronomische Gesellschaft, Kiel, March 8-12, 1993.

Tiersch, H. Stoll, D., Oleak, H., Böhringer, H. and MacGillivray, H.T., 1993b. 'Optical and Xray data of some Shakhbazian galaxy groups'. Poster presented at the 2nd General Meeting of the European Astronomical Society, Torun, August 18-21, 1993. 